\title{
Vault macro-element with equivalent trusses in global seismic analyses
}

\author{
Linda Giresini $^{* 1}$, Mauro Sassu ${ }^{1 a}$, Christoph Butenweg ${ }^{2 b}$, Valerio Alecci ${ }^{3 c}$ and Mario De Stefano ${ }^{3 d}$ \\ ${ }^{1}$ Department of Energy, Systems, Territory and Constructions Engineering Largo Lucio Lazzarino, 1, Pisa, University of Pisa, Italy \\ ${ }^{2}$ Lehrstuhl für Baustatik und Baudynamik, Mies-van-der-Rohe-Straße 152074 Aachen, RWTH, Germany \\ ${ }^{3}$ Department of Architecture, Piazza Brunelleschi 6, Firenze, University of Firenze, Italy
}

(Received September 1, 2016, Revised March 17, 2017, Accepted March 21, 2017)

\begin{abstract}
This paper proposes a quick and simplified method to describe masonry vaults in global seismic analyses of buildings. An equivalent macro-element constituted by a set of six trusses, two for each transverse, longitudinal and diagonal direction, is introduced. The equivalent trusses, whose stiffness is calculated by fully modeled vaults of different geometry, mechanical properties and boundary conditions, simulate the vault in both global analysis and local analysis, such as kinematic or rocking approaches. A parametric study was carried out to investigate the influence of geometrical characteristics and mechanical features on the equivalent stiffness values. The method was numerically validated by performing modal and transient analysis on a three naves-church in the elastic range. Vibration modes and displacement time-histories were compared showing satisfying agreement between the complete and the simplified models. This procedure is particularly useful in engineering practice because it allows to assess, in a simplified way, the effectiveness of strengthening interventions for reducing horizontal relative displacements between vault supports.
\end{abstract}

Keywords: vault; macro-element; equivalent stiffness; truss; churches

\section{Introduction}

Seismic assessment of historic buildings is the key to prevent possibly unrecoverable damages on the cultural heritage. Often, the architecture of historic structures is enriched by vaults of different typologies, which may have both structural and non-structural roles. The vaults geometry can be complex: from the simplest barrel vault, derived by the arch, to the more complex cross, dome or fan vaults. Their seismic vulnerability, especially when the building technique is in folio type (brick disposed along the shortest edge), is a well-known issue. Structural engineers are aware of difficulties in taking them into account when a numerical model has to be implemented. Finite elements modeling requires special efforts for two aspects: (i) the time needed to build the geometric model, generally intersection of irregular solids, (ii) the increased computational time in the global model due to the large number of elements and (iii) a possible numerical instability of the solution could emerge, due to the formation of local

*Corresponding author, Ph.D.

E-mail: linda.giresini@unipi.it

${ }^{a}$ Professor

E-mail: m.sassu@unipi.it

${ }^{\mathrm{b}}$ Professor

E-mail: butenweg@lbb.rwth-aachen.de

${ }^{\mathrm{c}} \mathrm{Ph} . \mathrm{D}$.

E-mail: valerio.alecci@unifi.it

${ }^{\mathrm{d}}$ Professor

E-mail: mario.destefano@unifi.it collapses in the vaults, which would not allow the convergence the global analyses. For that reasons, often the vaults have been modeled as equivalent diaphragms (Marseglia et al. 2014), but the identification of an equivalent thickness and boundary conditions arise uncertainties (Giresini et al. 2015). In many professional cases, the structural behaviour of the vaults is also simply neglected in global analysis and vaults are modeled only as equivalent masses. Nevertheless, the stiffening role of vaults in both local and global seismic assessment is relevant and needs to be properly considered. With this purpose, the method proposed in the present paper, particularly useful in engineering practice, is based on the possibility to model the masonry vaults as a system of equivalent trusses in terms of stiffness. This procedure, based on the generalization of the "macro-element approach", was first introduced in (Giresini et al. 2014) to perform complex numerical analyses in a simplified but effective way: the proposal of modeling vaults as equivalent macro-element arises from the methods of substituting masonry portions with frames (Magenes and La Fontana 1998) or macro-elements (Caliò et al. 2012, Caddemi et al. 2014, Caddemi et al. 2015, Giresini 2015a, Andreini et al. 2014, Pantò et al. 2016). Besides it, experimental tests on masonry cross vaults have been recently carried out to identify their stiffness in multiple directions (Rossi 2015).

In the present paper, the method to identify equivalent vaults as horizontal macro-elements is described and the aspects more critical are commented. Abaci of vaults as equivalent trusses (VET) are derived for several types of vaults from parametric analyses. Afterwards, the method is implemented in a whole three-naves basilica-type church. The simplified models, where the vaults are represented by 
equivalent trusses, are compared with full models, where the vaults are completely modeled with finite elements. With the simplified models is therefore possible not only to interpret the role of the vault in the as-built structure, but also rapidly performing checks to improve the seismic response by strengthening measures. Indeed, the computational time is strongly reduced and the attention is mostly focused on the effect of the vaults in the adjacent structures and the influence of strengthening techniques (i.e., steel tie-rods, FRP reinforcements, extradosal fill etc. Krajewski and Hojdys 2015). However, it could be noticed that, whether the structural behavior of arches or vaults have to be investigated, more non-linear analyses are needed, such as limit analysis in 2D-3D models (Alecci et al. 2016, D'Ayala and Tomasoni 2011, Milani et al. 2008). Moreover, recently advanced numerical tools were proposed to simulate the behaviour of the monumental buildings (Pantò et al. 2016). In this work the single vaults are analyzed in both linear and non-linear ranges, but only a linear analysis is performed for the comparison between the two church models. However, this approach can be extended to more significant non-linear models capable of taking into account this relevant masonry characteristic.

\section{Vault Equivalent Trusses (VET)}

\subsection{Definition of trusses equivalent to vaults}

The generic vault may be analyzed as system of equivalent trusses, whose in-plane dimensions are $L_{1}$ and $L_{2}$ (Fig. 1(a)). The equivalence is established in terms of stiffness, calculated by imposing displacements to a set of six hinged rigid rods in different directions. The plane of the trusses is chosen as that defined by the abutments. Fig. 1(a) displays the stiffness $K$ and the equivalent steel area $A$ of the trusses; the subscripts $l, t$ and $d$ respectively indicate the longitudinal, transverse and diagonal directions. The signs (+) and (-) stand for tensile and compression state. Finally, $N$ and $F$ symbolize internal force and reaction force, respectively.

For the definition of the diagonal truss stiffness, a sheartype mechanism is assumed (Fig. 1(b)). Nodes C and D are horizontally moved by $\delta_{1}$, inducing compression in B-D and tension in A-C diagonal. Assuming that both tension and compression states are active, the stiffness $K_{d}$ is given by

$$
\begin{aligned}
K_{d}=\frac{2 N_{d, d}^{-}}{\delta_{d, d}^{-}} & =\frac{2 N_{d, d}^{+}}{\delta_{d, d}^{+}}==\frac{\left|F_{1}\right|}{\cos \alpha_{d}} \cdot \frac{1}{\left|\delta_{1}\right| \cos \alpha_{d}} \\
& =\frac{\left|F_{1}\right|}{\left|\delta_{1}\right| \cdot \cos ^{2} \alpha_{d}}
\end{aligned}
$$

where $F_{1}$ is the sum of reaction forces generated by the imposed displacement $\delta_{1}$, and $\alpha_{d}$ the angle between the horizontal direction and the diagonal one in the deformed configuration.

For small displacements it can be assumed $\alpha \cong \alpha_{d}$. Due to the masonry poor tensile strength, rigorously only the truss in compression should be considered. Nevertheless, in the linear case and for small displacements, the material anisotropy can be neglected. Moreover, the need to consider both states arises once that modal analysis is requested, since the latter regards linear range.

The transverse (longitudinal) truss stiffness can be analogously obtained, i.e., by imposing displacements in transverse (longitudinal) direction. Fig. 1(c) depicts the closing mechanism in transverse direction. Nodes C and D are vertically moved by $\delta_{2}$, causing the sum of reaction forces $F_{2}$. Diagonal trusses are compressed and their stiffness can be expressed as

$$
K_{t}=\frac{N_{t}^{-}}{\delta_{2}^{-}}
$$

The relationship between the internal force in the transverse truss $N_{t}^{-}$and the reaction force $F_{2}$ is

$$
\frac{F_{2}}{2}=N_{t}^{-}+N_{d, t}^{-} \cos \alpha_{t}
$$

where $\alpha_{t}$ is the angle between the horizontal direction and the diagonal one in the deformed configuration. By substituting Eq. (3) in Eq. (2) one obtains

$$
K_{t}=\frac{\frac{F_{2}}{2}-N_{d, t}^{-} \cos \alpha_{t}}{\delta_{2}^{-}}
$$

The diagonal internal force $N_{d, t}^{-}$depends on the stiffness $K_{d}$

$$
N_{d, t}^{-}=\frac{K_{d}}{2} \delta_{d, t}^{-}=\frac{K_{d}}{2} \delta_{2}^{-} \sin \alpha
$$

The transverse stiffness is therefore

$$
K_{t}=\frac{\frac{F_{2}}{2}-\frac{K_{d}}{2} \delta_{2}^{-} \sin \alpha \cos \alpha_{t}}{\delta_{2}^{-}}
$$

Assuming $\alpha \cong \alpha_{t}$ and considering that $\sin 2 \alpha=$ $2 \sin \alpha \cos \alpha$, it follows

$$
K_{t}=\frac{F_{2}}{2 \delta_{2}^{-}}-K_{d} \frac{\sin 2 \alpha}{4}
$$

Therefore, the stiffness $K_{t}$ (or the corresponding longitudinal one $K_{l}$ ) is known once that the diagonal stiffness is determined.

The equivalent stiffness can be translated in terms of equivalent cross sectional area $A_{e q}$ or equivalent diameter $d_{e q}$. For instance, the equivalent area and the diameter $d_{d, e q}$ of the diagonal trusses are expressed by

$$
A_{d, e q}=\frac{\mathrm{K}_{d} \mathrm{~L}_{d}}{E_{s}} \quad d_{d, e q}=2 \sqrt{\frac{\mathrm{K}_{d} \mathrm{~L}_{d}}{\pi E_{s}}}
$$

where $L_{d}$ is the length of the diagonal and $E_{s}$ the steel Young's modulus. By considering the equivalent stiffness in longitudinal and transverse directions the equivalent steel area and diameter can be analogously calculated.

Once that the vault type is specified, together with geometric dimensions and mechanical parameters, VETs can be obtained by experimental tests or numerical simulations. In this paper, finite element models are used to 


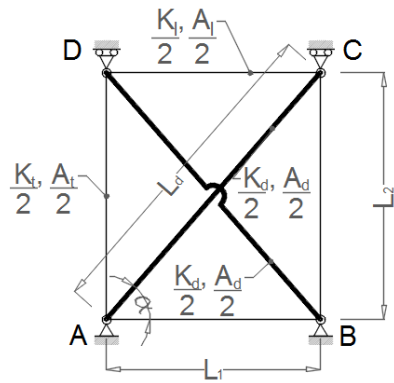

(a)

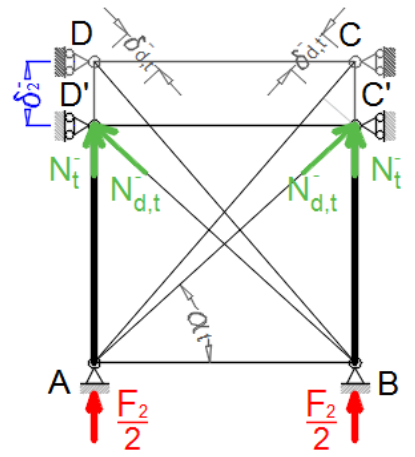

(c)

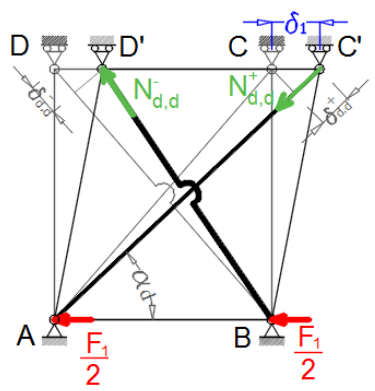

(b)
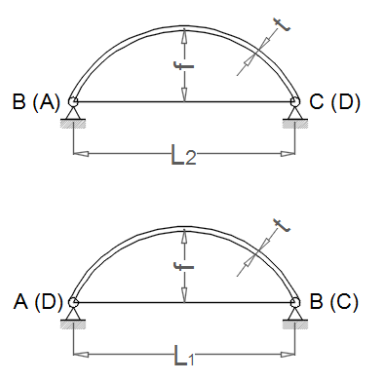

(d)
Fig. 1 Method for the determination of vault equivalent trusses (VET): (a) system of equivalent trusses in transverse, longitudinal and diagonal direction for a generic vault with in-plane dimensions $L_{1}$ and $L_{2}$; (b) diagonal truss stiffness obtained by shear-type deformation; (c) transverse (longitudinal) truss stiffness obtained by closing mechanism; (d) rise $f$ and thickness $t$ of the vault

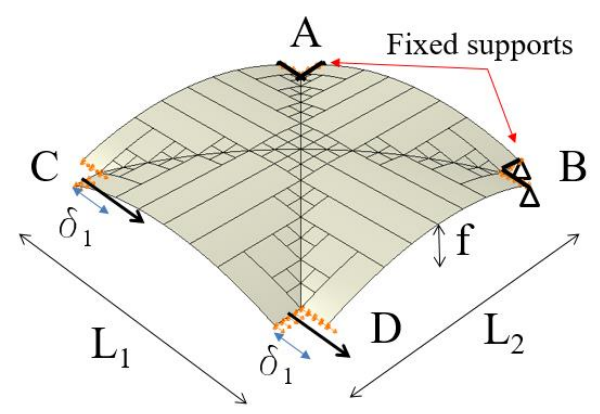

(a)

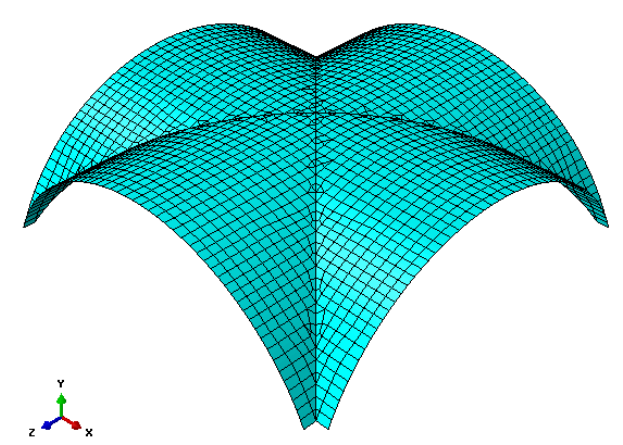

(b)

Fig. 2 Diagonal truss stiffness determination for a squared cross vault with different geometries: (a) boundary conditions and (b) model mesh calculate equivalent stiffness. Clearly, the possible presence of backfill strongly influences the stiffness value, and therefore it must be taken into account in the VET definition.

\subsection{Linear parametric analysis for different vaults types and geometries}

A parametric analysis of several vaults types and geometries is performed to draw charts useful in modeling vaults as equivalent trusses (VETs). Indeed, once that geometry of the vault, mechanical properties and boundary conditions are known, the stiffness values can be directly obtained by these charts and speed up the modeling process. To validate the method, the vaults fully modeled with finite elements have been compared to the trusses in global analysis. Further considerations on the validation process can be found in $\S 3.1$ and the comparisons are described in detail in $\S 4.1$.

Cross and dome vaults are analyzed, since they are very widespread in historical buildings and churches. For the sake of simplicity, only in-plane squared vaults are considered, namely $L_{1}=L_{2}=L$ (Fig. 1(a)), assuming the lack of backfill. Mechanical properties taken into account are those of brick masonry for existing buildings (NTC2008) and in particular: elastic modulus $1500 \mathrm{MPa}$, Poisson coefficient 0.15 . All vaults have specific weight 18 $\mathrm{kN} / \mathrm{m}^{3}$.

The adopted parameters are the in-plane length $L$, between 300 and $600 \mathrm{~cm}$, the ratio rise to in-plane length $f / L$, between 0 and 0.5 , and the thickness $t$ equal to 3,6 , $12 \mathrm{~cm}$ (Fig. 1(a)). Generally speaking, the boundary conditions strongly affect the equivalent stiffness, but for diagonal truss stiffness the results have been shown to be not so sensitive depending on the number of nodes where displacements are applied (Giresini et al. 2014).

Therefore, even though Sabouret's cracks cause a detachment of the vault from the adjacent structure, the value of diagonal stiffness does not appreciably changes. A first analysis is performed by applying displacements to the corners $\mathrm{C}$ and D, while A and B are hinged (Fig. 2(a)). The numerical analysis is performed with Abaqus CAE 6.12 (Abaqus CAE 6.12, User's and Theory Manuals); the finite elements are shell quadratic elements with 9 integration points through thickness and the average mesh size is $10-15$ cm (Fig. 2(b)).

The analysis is first performed by assuming linear material and the equivalent stiffness and steel diameters are obtained by Eqs. (1)-(7)-(8). The characterization of the diagonal trusses for a cross vault is depicted in Fig. 3.

The equivalent diagonal stiffness decreases whether the in-plane length increases for the same rise to length $f / L$ ratio - with a nearly linear behavior - and naturally is much lower for thinner vaults. Moreover, for lower $f / L$ ratios and same thickness $t$, the diagonal stiffness is higher since the vault shape is closer to a flat diaphragm. Concerning the equivalent steel diameter $d$, it does not appreciably change by increasing $L$ and with $f / L$ constant. Indeed, $d$ is proportional to the squared root of the product $K \bullet L$.

Longitudinal/transverse stiffness values for a squared 


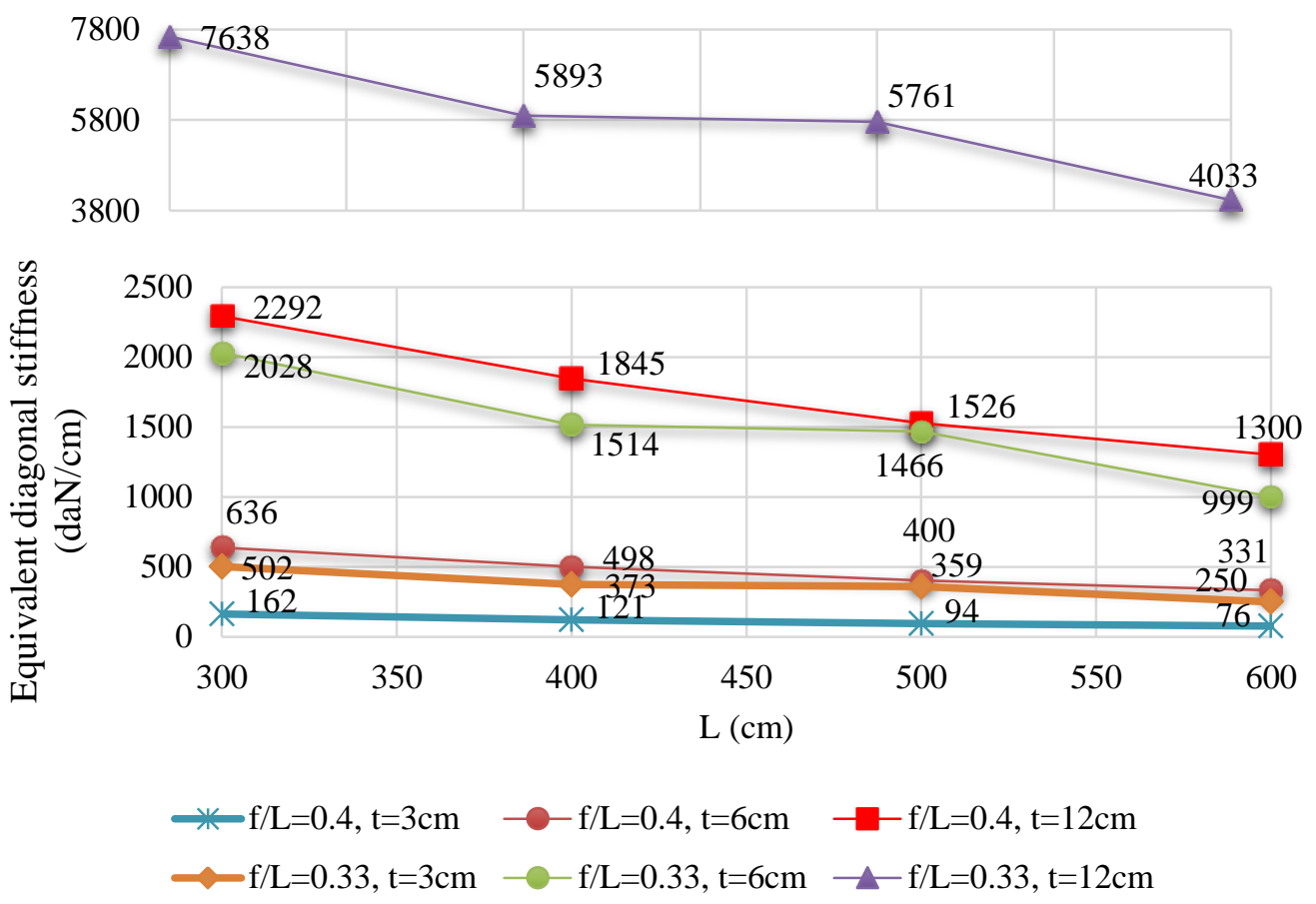

(a)

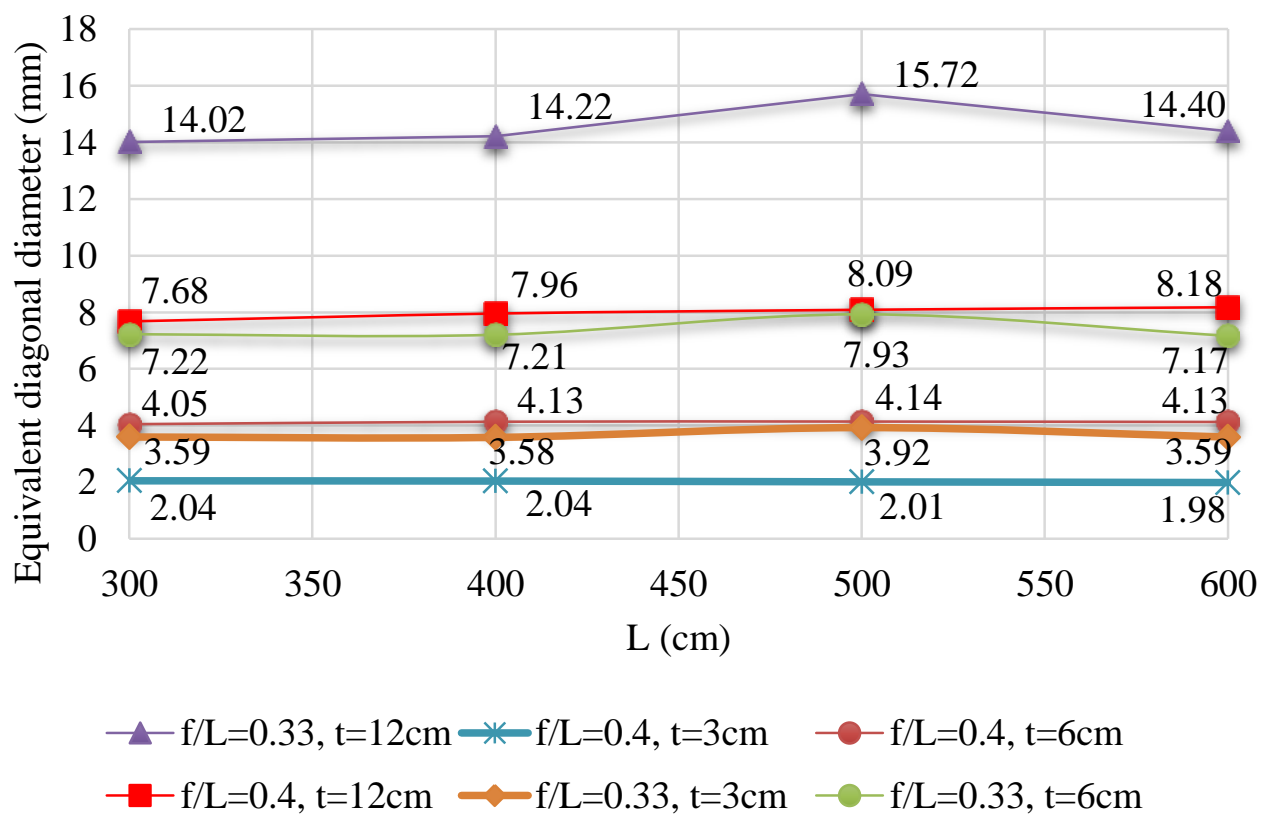

(b)

Fig. 3 Linear parametric analysis results for cross vaults: (a) equivalent diagonal stiffness - in-plane length relationship obtained by Eq. (1) and (b) equivalent diagonal steel diameter - in-plane length relationship for different rise to length ratios

cross vault having $L=300 \mathrm{~cm}$ are displayed in Fig. 4 . These values are plotted against the rise to length ratio $f / L$, with a lower limit value 0 , corresponding to a flat diaphragm with plane stress. The stiffness rapidly drops for higher $f / L$ ratios with non-linear behavior. When the ratio $f / L$ is constant, the longitudinal/transverse stiffness is markedly higher for thicker vaults. For instance, if $f / L=0.1$, from $\mathrm{t}=3 \mathrm{~cm}$ to $\mathrm{t}=12 \mathrm{~cm}$ one has a stiffness three orders of magnitude higher. The graph also shows the possible mistake can be made comparing a generic vault with a flat diaphragm. Moreover, in $\S 4.1$ a sensitivity analysis is performed to compare global analysis behavior of a church, where vaults are modeled first in their actual configuration and then as equivalent trusses or diaphragms.

Another possible parametric analysis considers different vaults boundary conditions. Generally, vaults are connected 


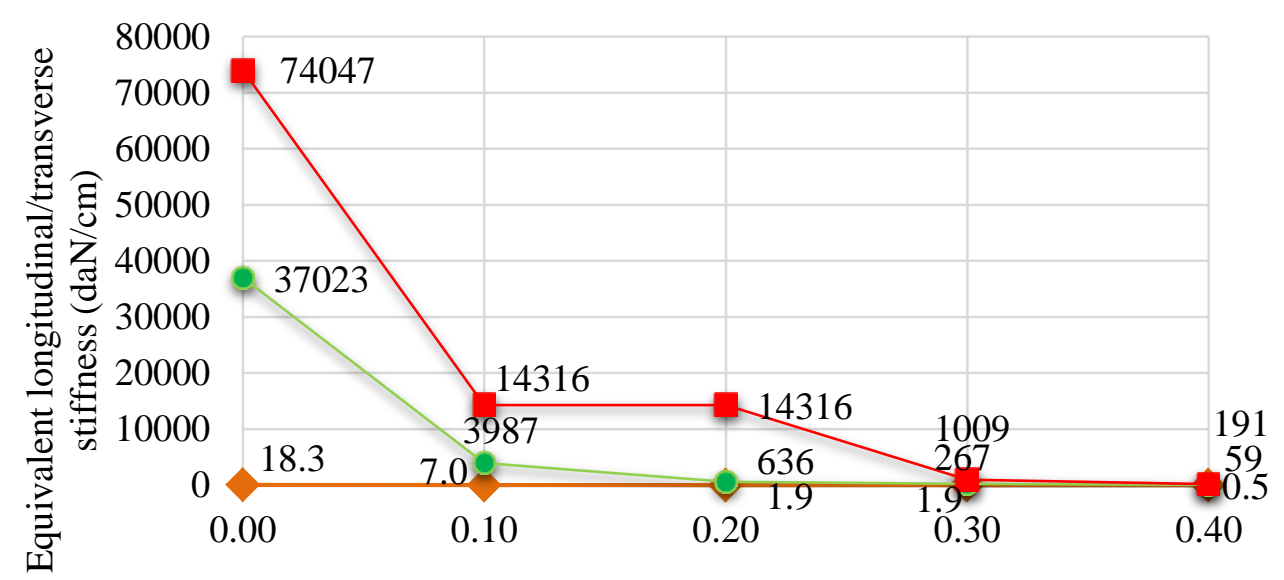

$\mathrm{f} / \mathrm{L}(-)$

$\neg \mathrm{t}=3 \mathrm{~cm} \quad-\mathrm{t}=6 \mathrm{~cm} \quad-\mathrm{t}=12 \mathrm{~cm}$

Fig. 4 Linear parametric analysis results for squared cross vaults with $\mathrm{L}=300 \mathrm{~cm}$ : equivalent longitudinal/transverse stiffness - rise/length relationship obtained by Eq. (7)

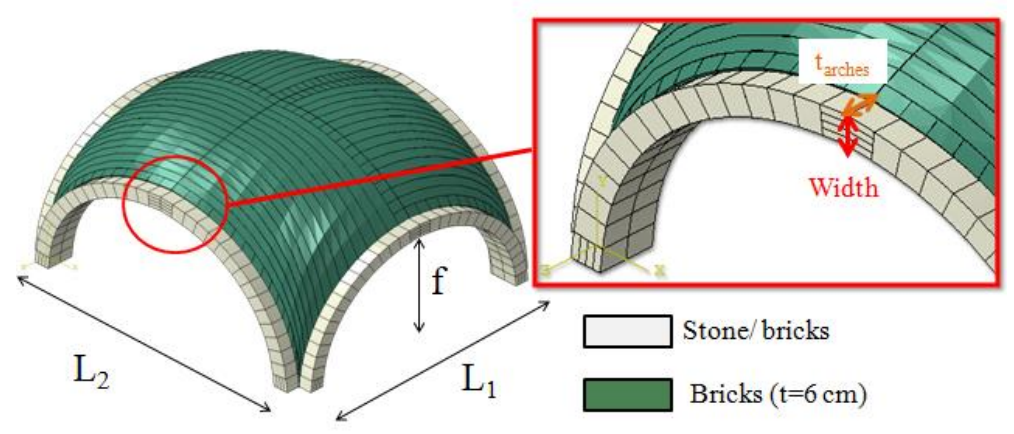

(a)

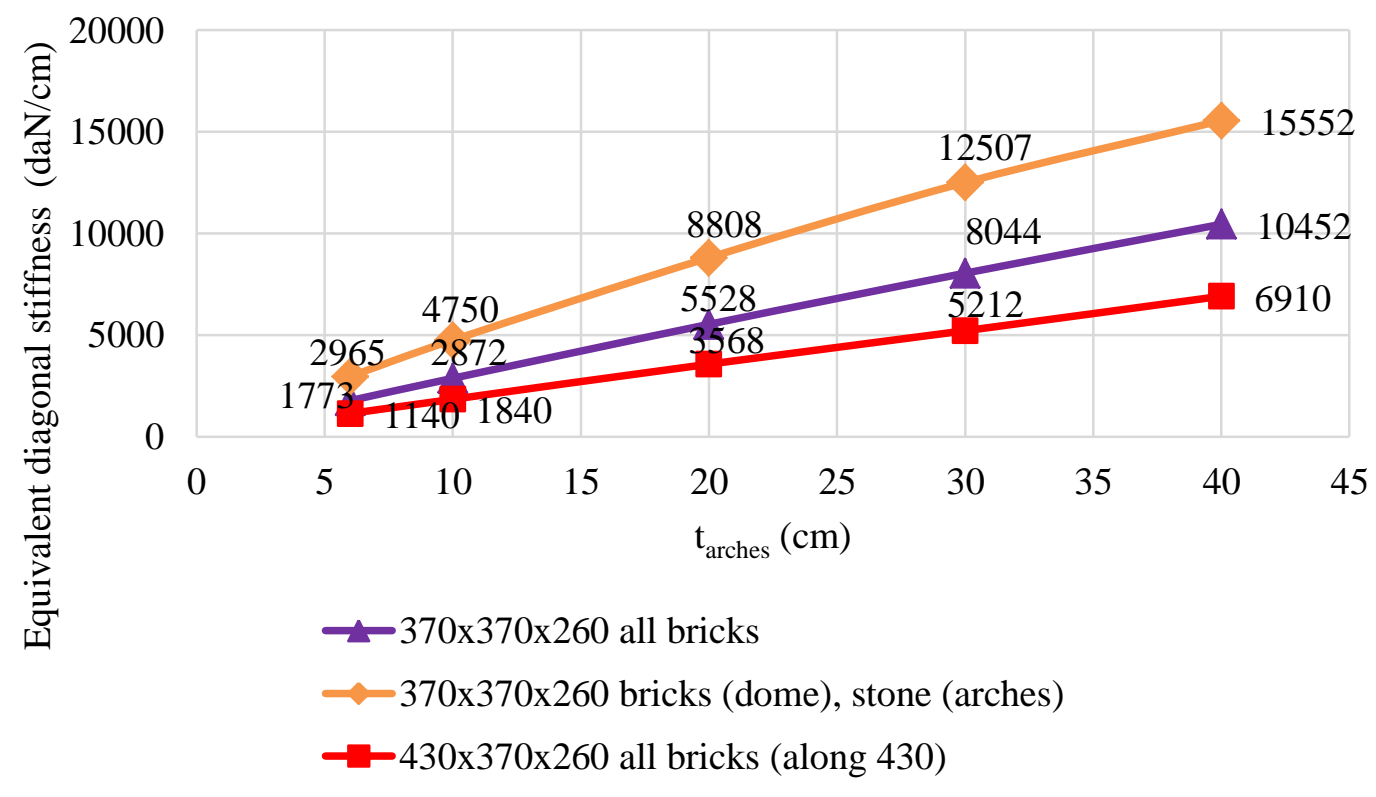

(b)

Fig. 5 Linear parametric analysis of dome vault with different adjacent arches materials: (a) vault geometry with indication of the arch thickness and width; (b) equivalent diagonal truss stiffness depending on arch thickness and material obtained with Eq. (1) 

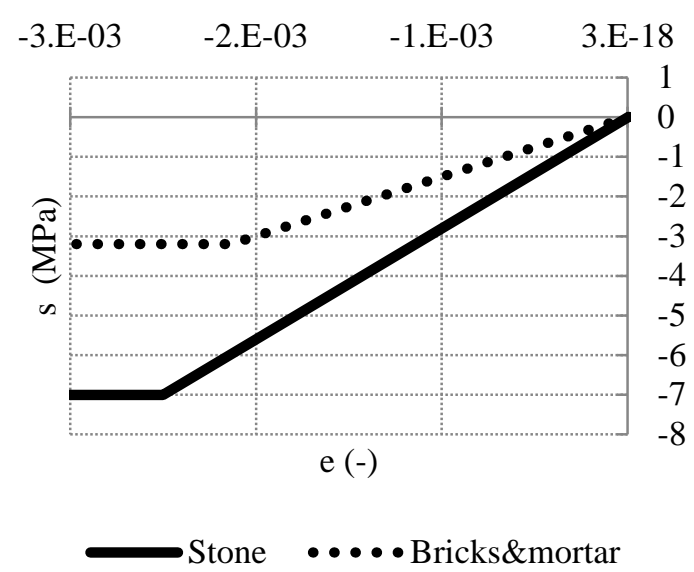

(a)

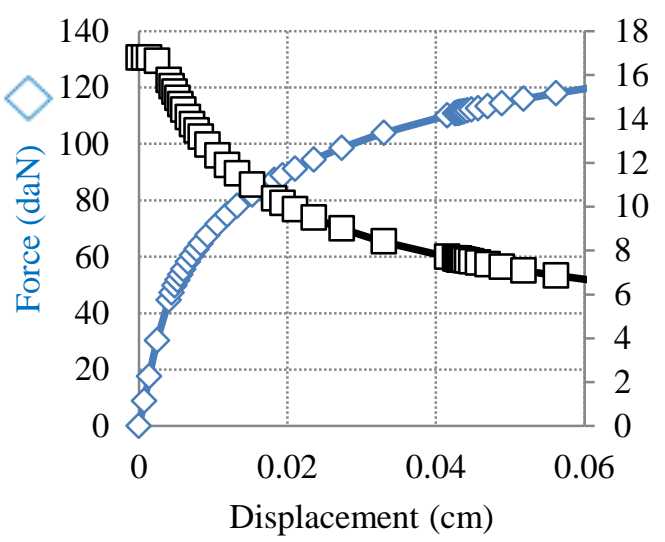

(c)

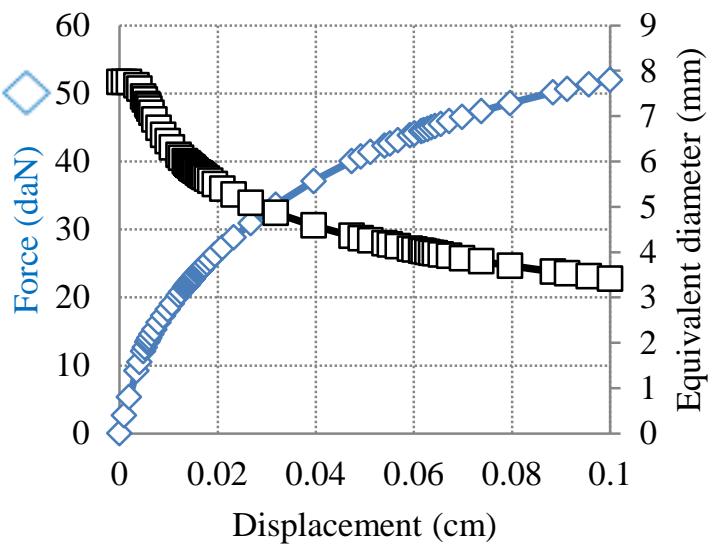

(e)

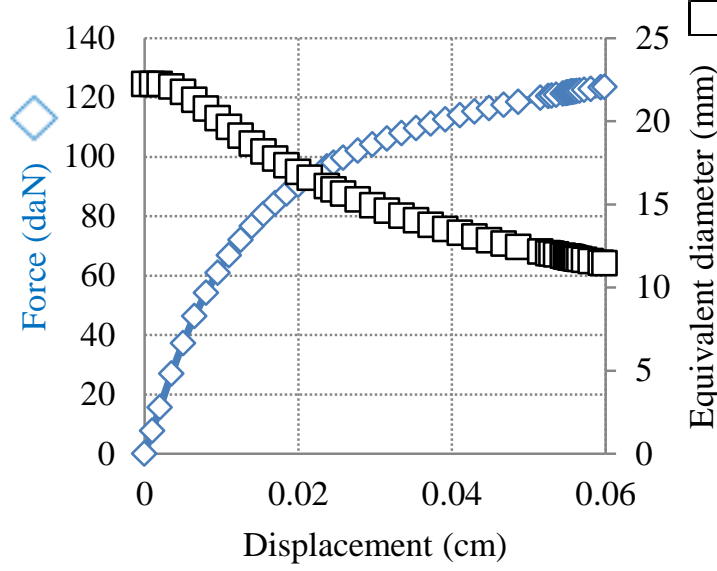

(b)

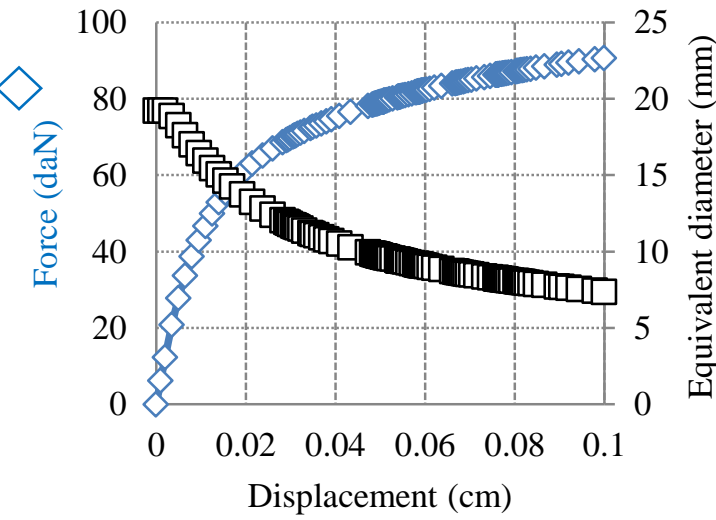

(d)

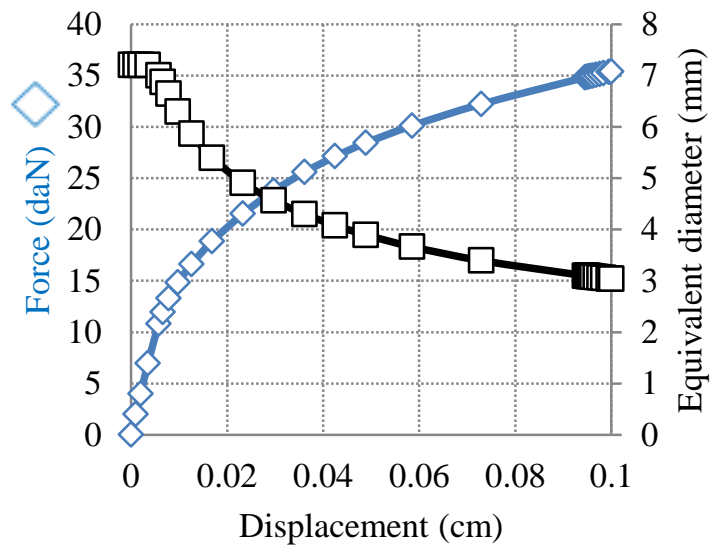

(f)

Fig. 6 Non-linear static analysis of dome vaults with $f / L=0.5$ : (a) compression stress-strain relationship (tensile strength $0.01 \mathrm{MPa}$ ); (b) equivalent diagonal diameter and sum of reaction forces (RF) for DV1 $L_{1}=L_{2}=370 \mathrm{~cm}$; (c) equivalent transverse/longitudinal diameter and sum of RF in closing mechanism (as in Fig. 1(c)) for DV1; (d) equivalent diagonal diameter and sum of RF for DV2 $L_{1}=430, L_{2}=370 \mathrm{~cm}$ loaded along the longer side; (e) equivalent transverse diameter and sum of RF in closing mechanism for DV2 along the shorter side; (f) equivalent transverse diameter and sum of RF in closing mechanism for DV2 along the longer side

to arches along the edges (Fig. 5). A dome vault (whose geometry is that of the vault of the case study presented in $\S$ 4.1 ) is analyzed to investigate the effect of different materials of adjacent arches.

Three cases are considered: (i) in-plane squared vault $L_{1}=L_{2}=370 \mathrm{~cm}$, with all bricks; (ii) same in-plane squared 
vault with vault made by bricks and stone arches; (iii) vault with $L_{1}=370 \mathrm{~cm}$ and $L_{2}=430 \mathrm{~cm}$, made all by bricks. All the side arches have ratio $f / L$ equal to 0.5 and the central dome vault is for all cases $6 \mathrm{~cm}$ thick. The second dome vault is not completely symmetric, since the side arches along the longitudinal direction have width of $40 \mathrm{~cm}$ and along the transverse direction width of $20 \mathrm{~cm}$. Besides the width of the side arches, Fig. 4(a) shows the thickness of the dome vault, in the examined cases constant and equal to $40 \mathrm{~cm}$. The bricks masonry elastic modulus is $1500 \mathrm{MPa}$, and the specific weight $18 \mathrm{kN} / \mathrm{m}^{3}$. The stone masonry elastic modulus is $1800 \mathrm{MPa}$ while the assumed specific weight is $22 \mathrm{kN} / \mathrm{m}^{3}$ (average values for existing masonry buildings obtained from (NTC2008)). For all cases, the crown height is $260 \mathrm{~cm}$ measured from the pendentives.

The considered boundary conditions are pinned nodes at the pendentives and displacements imposed to the whole side arch profile.

The values of diagonal truss stiffness are displayed in Fig. 4(b): the diagonal stiffness strongly decreases with shape ratio $L_{1} / L_{2}$ different from 1 . The case (iii)-where displacements are applied along the longer direction- is more flexible than case (i).

By contrast, if the vault is squared in-plane, stiffer side arches cause higher equivalent diagonal stiffness, as expected. In addition, the arch thickness strongly influences the diagonal stiffness.

\subsection{Non-linear parametric analysis for different vaults types and geometries}

An additional analysis is performed to define the stiffness variation when a non-linear masonry behavior is considered. An example is provided for the two dome vaults DV1 and DV2 (section 2.2) with arch thickness of $40 \mathrm{~cm}$ and stone arches. A brittle failure is assumed for tensile state, with a tensile strength equal to $0.01 \mathrm{MPa}$ for both brick and stone materials. Compressive strengths are assumed equal to 3.2 MPa for brick and 7.0 MPa for stone respectively. The maximum strain in compression is assumed equal to 3E.-3. The compressive elastic-plastic behavior, implemented in the Concrete Damaged Plasticity model in Abaqus (Abaqus CAE 6.12, User's and Theory Manuals), is shown in Fig. 6(a).

The non-linear analysis results are displayed in Fig. 6(b)-(c) for the squared dome vault DV1, and in Fig. 6(d)(e)-(f) for the asymmetric DV2. In all cases, it can be noticed that the equivalent steel diameter markedly drops for small displacement, of the order of millimeter, due to the about null tensile strength assumed. Concerning the diagonal stiffness, if the vault is not squared in-plane, the initial stiffness is much lower but the rate of reduction is less rapid than for DV1 (Fig. 6(b)-(d)). The convergence is obtained for a lower displacement value for DV1, $0.06 \mathrm{~cm}$ against $0.1 \mathrm{~cm}$ of DV2.

Referring to the longitudinal-transverse stiffness in closing mechanism - the opening mechanism has negligible stiffness if nearly zero tensile strength is assumed - stiffness values are much lower than diagonal ones, especially for the asymmetric vault. The initial stiffness is one order of magnitude higher for DV1, but the reduction rate at the same common maximum displacement $(=0.06 \mathrm{~cm})$ is similar. The equivalent truss in longitudinal direction is slightly more flexible than in the transverse one for the asymmetric DV2, due to the more marked bending effect in the longer direction.

\section{VET analysıs for seismic vulnerabılity assessment}

The idea to model vaults as macro-element made by equivalent trusses support the need to evaluate the role of the vaults in the seismic response of historic buildings. The main purpose is to reduce modeling and computational time, especially for complex and large structures. Vaults are flexible diaphragms of different geometries, mechanical properties and boundary conditions with adjacent structures. Vaults equivalent trusses (VETs) can be implemented in both global and local analysis in commercial programs or may be included in local analysis, as rocking approaches or kinematic analysis for façades or other structural elements restrained by vaults. The latter ones are the tool indicated by the Italian codes for assessing seismic vulnerability of existing masonry structures. In this paragraph, some criteria to include VETs in the analysis of historic masonry structures are discussed.

\subsection{VET in global analysis of historic buildings}

The validation process of inserting VET in place of complete vaults can be numerically carried out by comparing full-modeled church (as those displayed in Fig. 7) to VET simplified models, where equivalent trusses substitute the vaults. Naturally, it is not simple to identify for each vault the boundary conditions with adjacent elements to obtain realistic stiffness values, but numerical comparisons can be performed by assuming a perfect connection between nodes of the vault and nodes of the adjacent structures. Indeed, the purpose here is of numerically validating the method, whereas the stiffness abaci can take into account more in-depth different boundary conditions.

Two types of comparisons are performed: (i) modal analysis and (ii) global time-history analysis. In the first case, natural frequencies and modal participation factors are considered; indeed, the modal analysis, although simple and linear, can give preliminary information on the dynamic behavior. In the time-history analysis, relative displacements of vaults support in different directions are monitored. Also in this case, only a linear analysis has been performed, due to the uncertainties in defining non-linear behavior for large structures and to the spirit of simplification that leads the method. Moreover, the aim is to evaluate displacements peaks that lead to stress peaks in vaults and masonry panels, in order to identify the most critical portions.

\subsection{VETs in local analysis}

VETs in local analysis can be useful to model vault 


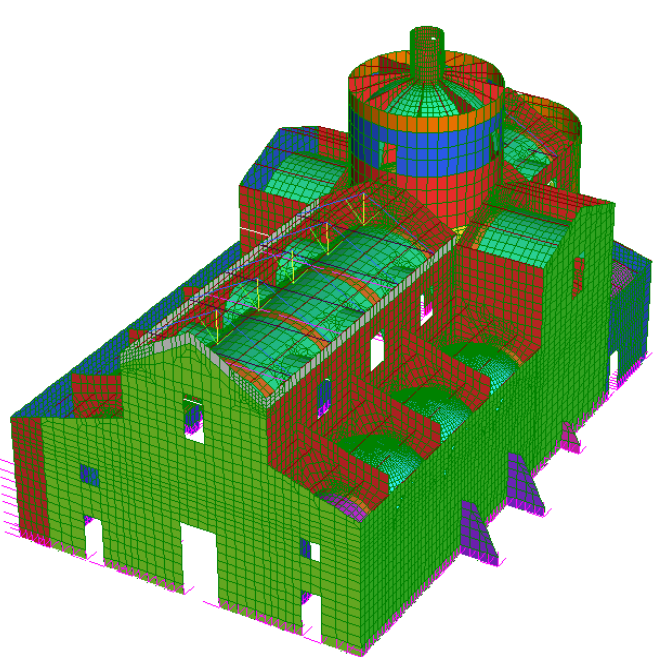

(a)

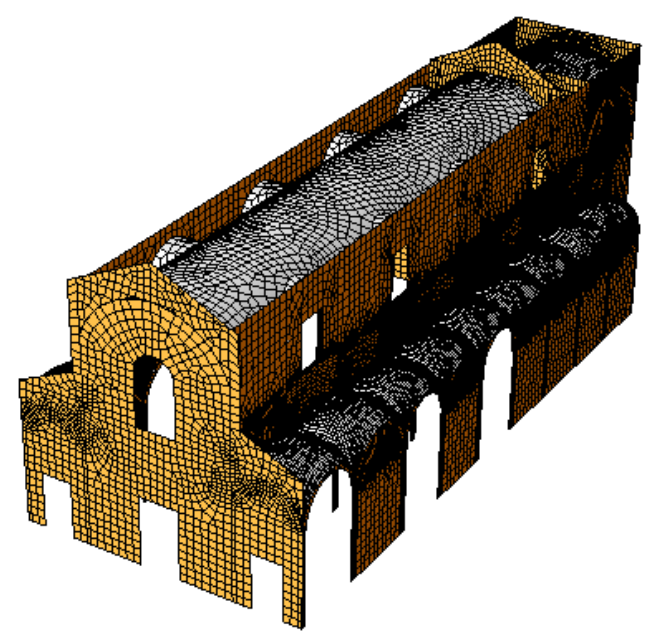

(b)

Fig. 7 Finite elements models of historic churches: (a) Santa Gemma church in Goriano Sicoli (Andreini et al. 2010); (b) San Frediano church in Pisa
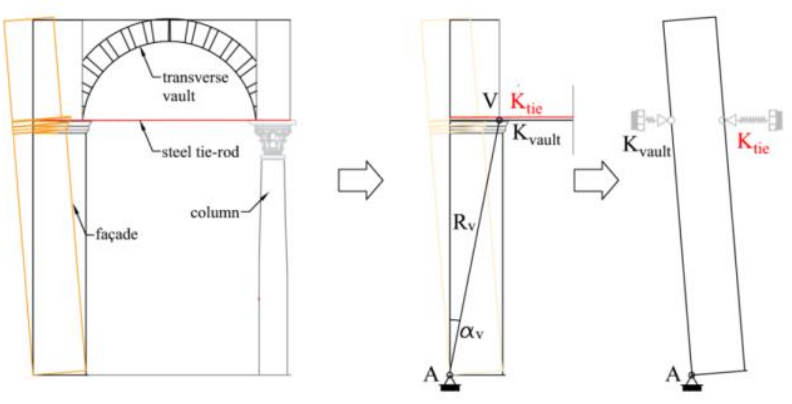

Fig. 8 Vaults equivalent trusses connected to masonry façade (adapted from Giresini et al. 2015)

connected to masonry panels that can be assimilated to rigid blocks. Generally, existing masonry buildings are regarded as set of macro-elements, each of them composed by rigid blocks due to the poor connections between structural elements.

Masonry façades, for instance, can be studied as rigid blocks oscillating around a horizontal hinge. Evidently, possible vaults connected play role in the seismic response. These kind of structures can be studied with kinematic linear/nonlinear approaches (NTC2008) and rocking analysis (Giresini et al. 2016, DeJong and Dimitrakopoulos 2014). A spring with equivalent stiffness, obtained with the procedure illustrated in $\S 2.1$, represents the vault connected to the rigid block (Fig. 8). The VET-model might be easily expanded with other constitutive laws: the stiffness can be different in tension and in compression but constant, or may vanish for a limit displacement, or can follow a specific constitutive law (Giresini and Sassu 2016). In addition, strengthening measures, like steel tie-rods acting only in tension, might be modeled with this procedure.

\section{Numerical case study}

In this paragraph, an application of the use of VETs in global and local analysis is performed. An historic basilica church is analyzed with two FE models: one with fullymodeled vaults and another with VETs in place of the vaults, comparing the results of the dynamic analyses.

\subsection{Global analysis of a historic basilica church}

The church of San Frediano in Pisa (Italy), was considered to validate the method of substituting equivalent trusses in global analysis. The plan of the church is shown in Fig. 9(a).

The structure is a basilica-type church with three naves, covered by dome vaults and barrel vault with lunettes in the central nave. The church has dimensions $41 \times 15 \times 16 \mathrm{~m}$ (length $\times$ width $\times$ maximum tympanum height) and it is considered structurally isolated. The church is made up by ashlar stone (façade and walls), granite (columns), bricks and mortar (vaults).

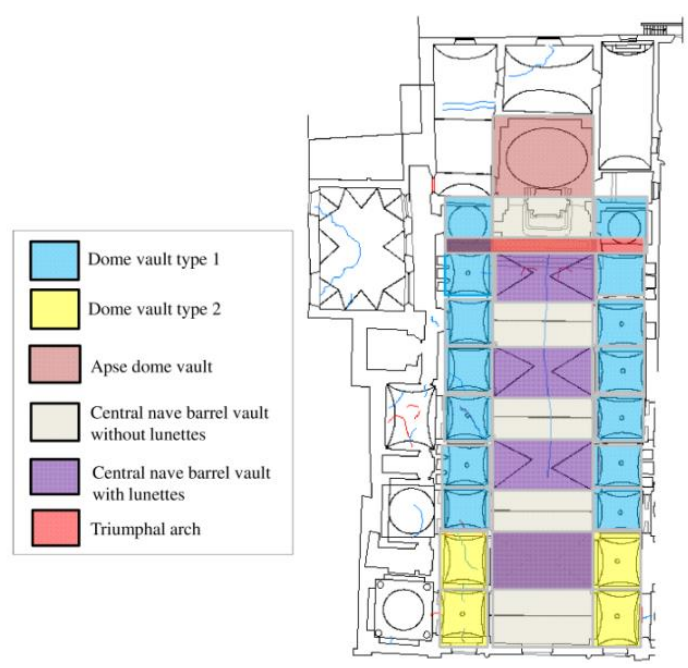

(a)

Fig. 9 Vaults typologies in San Frediano church: (a) in-plane disposition; (b) lateral naves and apse vaults with dimensions in $\mathrm{cm}$; (c) central nave barrel vault subdivided in 8 barrel vaults 


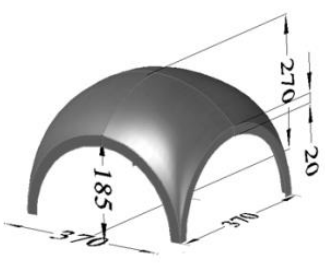

Dome vault type 1
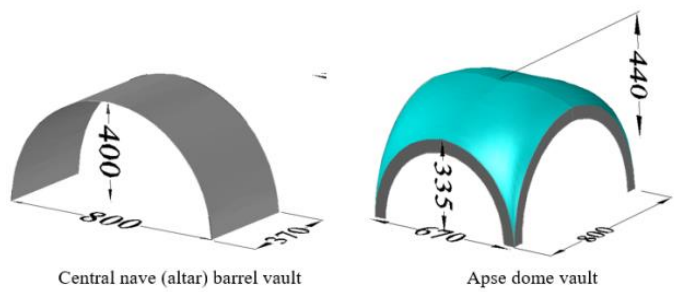

(b)

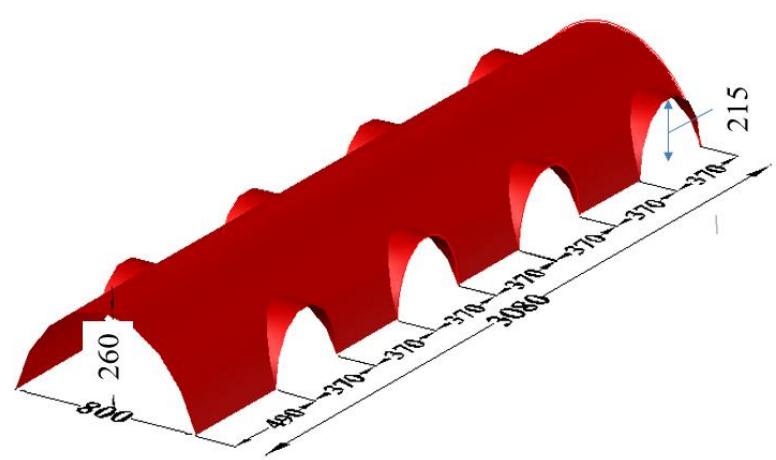

Central nave barrel vault

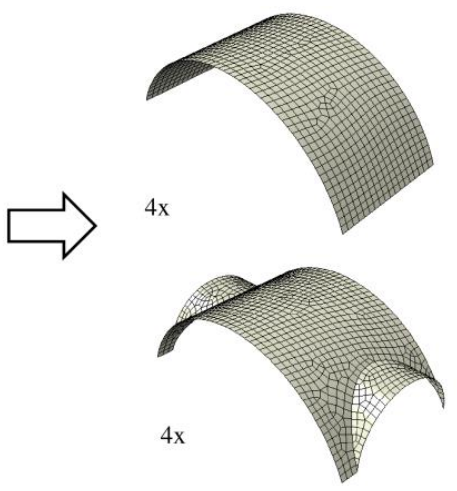

(c)

Fig. 9 Continued

The in-plan disposition of the vaults and their geometrical dimensions are displayed in Fig. 9. The following mechanical properties were considered: Young modulus $50000 \mathrm{MPa}$ (granite), $1500 \mathrm{MPa}$ (bricks and mortar), $2800 \mathrm{MPa}$ (stone); Poisson coefficient 0.15 for all materials; specific weight $27 \mathrm{kN} / \mathrm{m}^{3}$ (granite), $18 \mathrm{kN} / \mathrm{m}^{3}$ (bricks and mortar), $22 \mathrm{kN} / \mathrm{m}^{3}$ (stone). There are five typologies of $6 \mathrm{~cm}$ thick vaults in the San Frediano church:

- $\mathrm{n}^{\circ} 14$ dome vaults of dimensions $370 \times 370 \times 270 \mathrm{~cm}$ (plan longitudinal length, plan transverse width and rise at the crown respectively) in the lateral naves, labeled dome vault type 1 or DV1.

- $\mathrm{n}^{\circ} 4$ dome vaults adjacent to the main façade of dimensions $430 \times 370 \times 270 \mathrm{~cm}$ in the lateral naves, labeled dome vault type 2 or DV2.

- apse dome vault of dimensions $670 \times 800 \times 440 \mathrm{~cm}$;

- altar barrel vault of dimensions $370 \times 800 \times 400 \mathrm{~cm}$;

- central nave barrel vault, modeled as set of smaller barrel vaults, with and without lunettes, of dimensions $430 / 370 \times 800 \times 260 \mathrm{~cm}$.

Table 1 Vaults equivalent trusses stiffness of the vaults in San Frediano church. Diag=diagonal direction, long=longitudinal direction (X direction, Fig. 10(a)), transv=transverse direction (Y direction, Fig. 10(a))

\begin{tabular}{|c|c|c|c|c|c|c|}
\hline & & Vault & $\begin{array}{c}\mathrm{K}_{\mathrm{eq}} \\
(\mathrm{daN} / \mathrm{cm}) \\
\end{array}$ & $\begin{array}{c}\mathrm{d}_{\mathrm{eq}} \\
(\mathrm{mm})\end{array}$ & $\mathrm{K}_{\mathrm{eq}} / 2$ & $\begin{array}{c}\mathrm{d}_{\mathrm{eq}} \\
\left(\mathrm{K}_{\mathrm{eq}} / 2\right)\end{array}$ \\
\hline \multirow{6}{*}{ 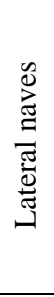 } & \multirow{3}{*}{ 方 } & diag & 15552 & 22.2 & 7776 & 15.7 \\
\hline & & long & 12555 & 16.8 & 6278 & 11.9 \\
\hline & & transv & 12555 & 16.8 & 6278 & 11.9 \\
\hline & \multirow{3}{*}{$\stackrel{2}{2}$} & diag & 10060 & 18.6 & 5030 & 13.1 \\
\hline & & long & 9882 & 14.9 & 4941 & 10.5 \\
\hline & & transv & 13663 & 17.5 & 6832 & 12.4 \\
\hline \multirow{3}{*}{$\begin{array}{l}\infty \\
\stackrel{2}{\gtrless}\end{array}$} & \multirow{3}{*}{ ' } & diag & 56445 & 59.7 & 28223 & 42.2 \\
\hline & & long & 138719 & 74.8 & 69360 & 52.9 \\
\hline & & transv & 54208 & 51.3 & 27104 & 36.3 \\
\hline \multirow{12}{*}{ 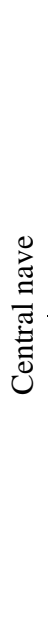 } & \multirow{6}{*}{$\begin{array}{l}\stackrel{尺}{\tilde{丶}} \\
\underset{\infty}{8} \\
\stackrel{\infty}{0}\end{array}$} & Barrel_lun_diag & 62206 & 57.7 & 31103 & 40.8 \\
\hline & & Barrel_lun_long & 172806 & 62.3 & 86403 & 44.0 \\
\hline & & Barrel_lun_transv & 15240 & 27.2 & 7620 & 19.2 \\
\hline & & Barrel_diag & 81209 & 65.9 & 40604 & 46.6 \\
\hline & & Barrel_long & 248612 & 74.7 & $\begin{array}{c}12430 \\
6\end{array}$ & 52.8 \\
\hline & & Barrel_transv & 9626 & 21.6 & 4813 & 15.3 \\
\hline & \multirow{6}{*}{ 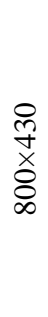 } & Barrel_lun_diag & 54977 & 55.0 & 27488 & 38.9 \\
\hline & & Barrel_lun_long & 152189 & 63.0 & 76095 & 44.5 \\
\hline & & Barrel_lun_transv & 17441 & 29.1 & 8720 & 20.6 \\
\hline & & Barrel_diag & 74086 & 63.9 & 37043 & 45.2 \\
\hline & & Barrel_long & 223165 & 76.3 & $\begin{array}{c}11158 \\
3\end{array}$ & 53.9 \\
\hline & & Barrel_transv & 12611 & 24.7 & 6306 & 17.5 \\
\hline \multicolumn{3}{|c|}{$\begin{array}{c}\text { Complete longitudinal barrel } \\
\text { vault }\end{array}$} & 21413 & 63.2 & 10707 & 44.7 \\
\hline
\end{tabular}

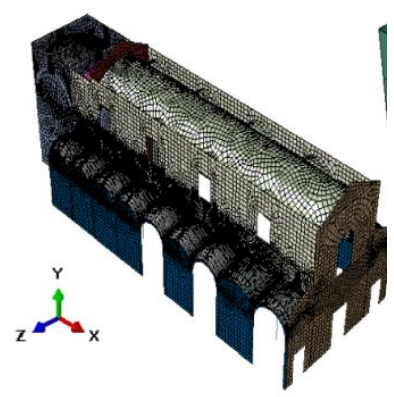

(a)

Fig. 10 FEM models: (a) church fully modeled actual; (b) VET model; (c) church with preventive steel tie-rods in complete configuration in lateral naves 


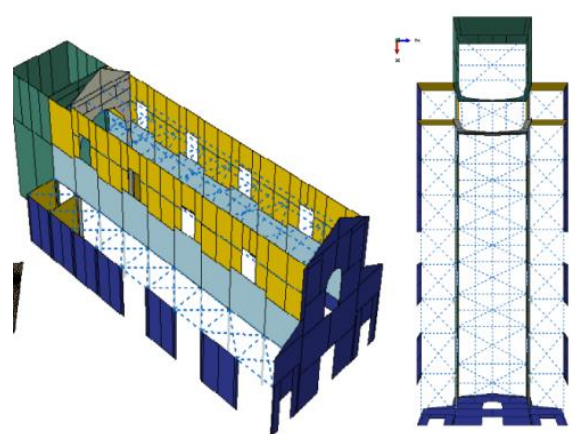

(b)

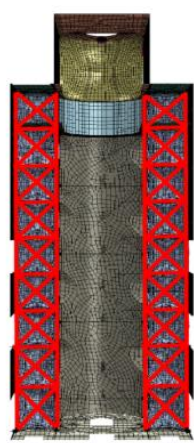

(c)

Fig. 10 Continued

The diagonal equivalent stiffness for DV2 and for the apse vault have been obtained as average between the case in which it is calculated imposing a displacement along the vault side with $430 \mathrm{~cm}$ and that in which the displacement is imposed along the side $370 \mathrm{~cm}$-long. The stiffness values are reported in Table 1.

The simplified model, named VET model, is compared to the so-called full model, where vaults are modeled with finite elements recreating their real geometry, in terms of modal analysis and time-history analysis.

\subsubsection{Modal analysis}

Two simplified models with VETs have been considered: (i) VETs in place of vaults and additional masses to recreate the removed mass of the vaults and (ii) VETs in place of vaults without additional masses. The diagonal stiffness was fully considered in tension and in compression.

In case (i), the additional masses are concentrated at the extremities of the trusses. 230 modes were necessary to reach about $85 \%$ of the total mass for the two main horizontal directions of the building. A sensitivity analysis was also performed by adopting in place of vaults flat diaphragms with variable thickness: $6 \mathrm{~cm}$ like in the as-built configuration, and $60 \mathrm{~cm}$ with properly reduced specific weight, not to alter the mass distribution. Finally, a model without vaults has been analyzed, by increasing the specific weight to consider the removed masses.

Results for the transverse and longitudinal direction are reported in Table 2 and Table 3, respectively. Those tables list, for each model, the frequency in $\mathrm{Z}$ (or $\mathrm{X}$ ) direction (transverse or longitudinal, Fig. 10(a)) fz (or fx), the percentage of participant mass $\mathrm{Mz}$ (or Mx) and in the third column the percentage difference between the equivalent models and the complete model. The VET model without additional masses shows the best correspondence with the complete (actual) model, in terms of natural frequencies and mode shapes. The difference of the first natural frequency is lower than $8 \%$ of the first natural frequency along the transverse direction and the corresponding modal mass. In the longitudinal direction, the difference of the first natural frequency is $6 \%$ while the corresponding mass is higher. If additional masses are considered with VETs, the natural frequency along the longitudinal direction is acceptable $(<10 \%)$, while in the transverse direction is $17 \%$.

When the vaults are modeled as horizontal slabs, in transverse direction the agreement is good in terms of both modal masses and natural frequencies (with the exception of natural frequency of the model with $60 \mathrm{~cm}$ thick slabs), while a poor agreement in longitudinal direction results.

The model with horizontal slabs is much more rigid than the complete model (Table 3) in longitudinal direction, (a difference of about $+18 \%$ and $+48 \%$ for the natural frequencies of the model with $6 \mathrm{~cm}$ and $60 \mathrm{~cm}$ respectively) and the associated mass much lower. The latter aspect is due to the small activated mass concentrated in the diaphragms, therefore the model with horizontal slabs does not give the global church response in longitudinal direction, where anyway the relative deformations of vaults are lower. By contrast, the longitudinal response is correctly reproduced by the VETs model without additional masses

Table 1 Comparisons between natural frequencies and modal masses in the transverse direction of the building

\begin{tabular}{ccccc}
\hline \hline Model & $\mathrm{fz}(\mathrm{Hz})$ & $\begin{array}{c}\mathrm{Mz} \\
(\% \text { tot })\end{array}$ & $\begin{array}{c}\% \text { Actual } \\
\mathrm{fz}\end{array}$ & $\begin{array}{c}\% \text { Actual } \\
\mathrm{Mz}\end{array}$ \\
\hline Complete model & 1.90 & 42.36 & 0.00 & 0.00 \\
$\quad$ Simplified & 1.82 & 38.86 & -4.33 & -8.27 \\
$\begin{array}{c}\text { Simplified + add. } \\
\text { masses }\end{array}$ & 1.56 & 37.63 & -17.85 & -11.16 \\
$\begin{array}{c}\text { Horizontal slabs 6 } \\
\text { cm }\end{array}$ & 1.76 & 42.90 & -7.50 & 1.26 \\
$\begin{array}{c}\text { Horizontal slabs 60 } \\
\text { cm }\end{array}$ & 2.53 & 45.80 & 32.90 & 8.11 \\
No vaults & 0.56 & 18.53 & -70.71 & -56.27 \\
\hline
\end{tabular}

Table 2 Comparisons between natural frequencies and modal masses in the longitudinal direction of the building

\begin{tabular}{|c|c|c|c|c|c|c|c|}
\hline Model & $\begin{array}{c}\mathrm{fx} 1 \\
(\mathrm{~Hz})\end{array}$ & $\begin{array}{c}\mathrm{Mx} 1 \\
(\% \text { tot })\end{array}$ & $\begin{array}{c}\% \\
\text { Actual } \\
\text { fx1 }\end{array}$ & $\begin{array}{c}\mathrm{fx} 2 \\
(\mathrm{~Hz})\end{array}$ & $\begin{array}{c}\text { Mx2 } \\
(\% \text { tot })\end{array}$ & $\begin{array}{c}\% \\
\text { Actual } \\
\mathrm{fx} 2\end{array}$ & $\begin{array}{c}\text { Sum Mx } \\
\text { (\%tot) }\end{array}$ \\
\hline $\begin{array}{c}\text { Complete } \\
\text { model }\end{array}$ & 4.12 & 36.79 & 0.00 & 4.36 & 11.99 & 0 & 48.78 \\
\hline Simplified & 3.87 & 56.06 & -6.00 & - & - & - & 56.06 \\
\hline $\begin{array}{c}\text { Simplif. + } \\
\text { add.masses }\end{array}$ & 3.75 & 26.25 & -8.89 & 3.82 & 21.96 & -12.30 & 48.21 \\
\hline $\begin{array}{l}\text { Horizontal } \\
\text { slabs } 6 \mathrm{~cm}\end{array}$ & 4.88 & 11.25 & 18.54 & 4.96 & 8.12 & 13.80 & 19.36 \\
\hline $\begin{array}{l}\text { Horiz. slabs } \\
\quad 60 \mathrm{~cm}\end{array}$ & 6.09 & 26.82 & 48.09 & 7.17 & 34.77 & 64.51 & 61.59 \\
\hline No vaults & 3.50 & 47.82 & -15.08 & 3.51 & 10.60 & -19.35 & 58.42 \\
\hline
\end{tabular}


(second row of Fig. 11). Moreover, the simplified model has the same deformed shape as the complete model regarding the walls above the colonnade. These relative displacements of the central vault abutments, which cause a brittle failure, are particularly dangerous since they can determine the vault collapse: it is relevant that VETs model can efficiently describe this aspect.

For these reasons, the VET model can be recommended for simplified analysis, while horizontal slabs or simple equivalent masses neglecting the real vault geometry should be avoided.

\subsubsection{Transient analysis}

Global transient analysis has been performed by applying acceleration time-histories at the base of the church. The linear range is considered, as the interest is focused on small relative displacements and on peak displacements. Since the maximum effects have to be considered, three accelerograms are sufficient to perform dynamic analysis (European Committee for Standardization (2003) Eurocode 8). The accelerograms are spectrumcompatible with response spectrum with return period of 75 years and behavior factor 1.5, soil $\mathrm{C}$ and topographic category T1. A fourth accelerogram was considered by doubling the acceleration values to check the response with the same frequency content but different intensity. For further details on the acceleration time-histories, refer to (Giresini et al. 2014). Relative displacements of the vaults
Complete model $-\mathrm{f}_{\mathrm{X}}=4.12 \mathrm{~Hz}, \mathrm{M}_{\mathrm{X}}=36.79 \%$

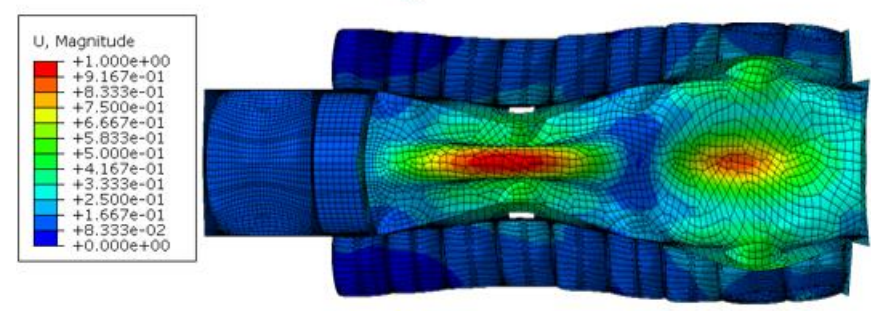

Simplified $-\mathrm{f}_{\mathrm{X}}=3.87 \mathrm{~Hz}, \mathrm{M}_{\mathrm{X}}=56.06 \%$

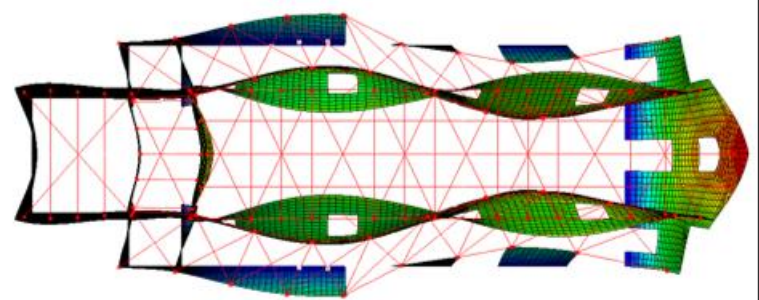

Simplified + masses $-f_{X}=3.75 \mathrm{~Hz}, M_{X}=26.25 \%$

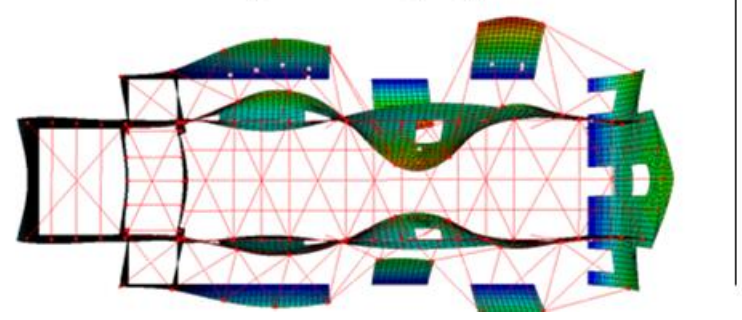

Horizontal slabs of thickness $6 \mathrm{~cm}-\mathrm{f}_{\mathrm{X}}=4.88 \mathrm{~Hz}, \mathrm{M}_{\mathrm{X}}=11.25 \%$
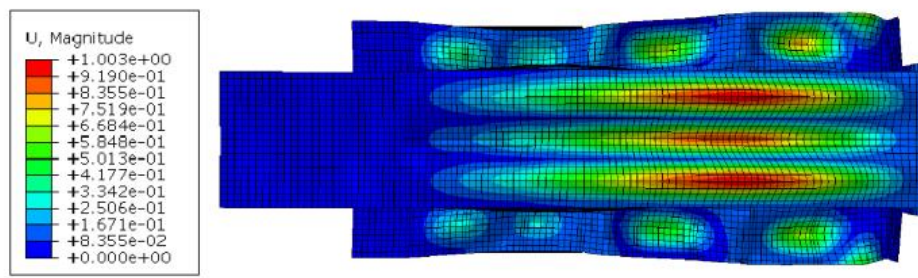

Complete model $-\mathrm{f}_{\mathrm{Z}}=1.90 \mathrm{~Hz}, \mathrm{M}_{\mathrm{Z}}=42.36 \%$

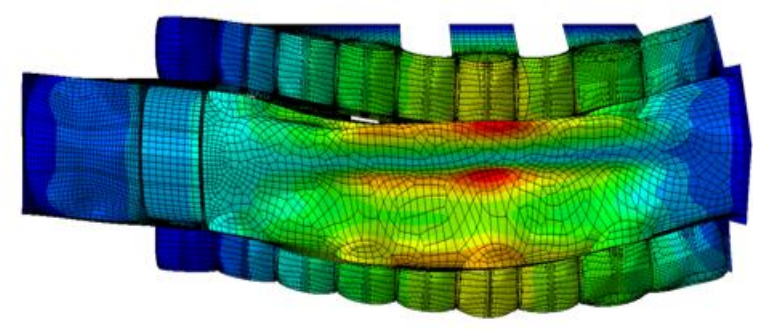

Simplified $-\mathrm{f}_{\mathrm{Z}}=1.82 \mathrm{~Hz}, \mathrm{M}_{\mathrm{Z}}=38.86 \%$

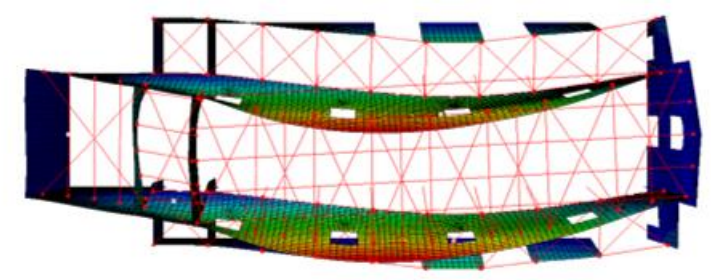

Simplified + masses $-\mathrm{f}_{\mathrm{Z}}=1.56 \mathrm{~Hz}, \mathrm{M}_{\mathrm{Z}}=37.63 \%$

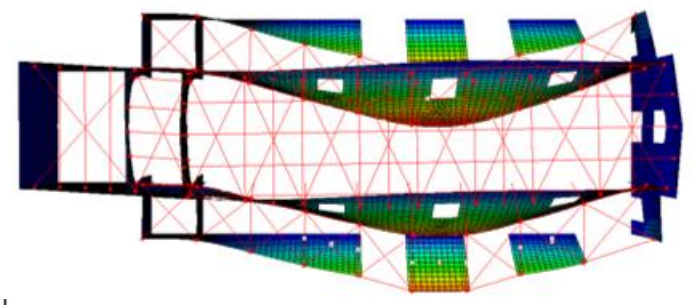

Horizontal slabs of thickness $60 \mathrm{~cm}-\mathrm{f}_{\mathrm{X}}=6.09 \mathrm{~Hz}, \mathrm{M}_{\mathrm{X}}=26.82 \%$

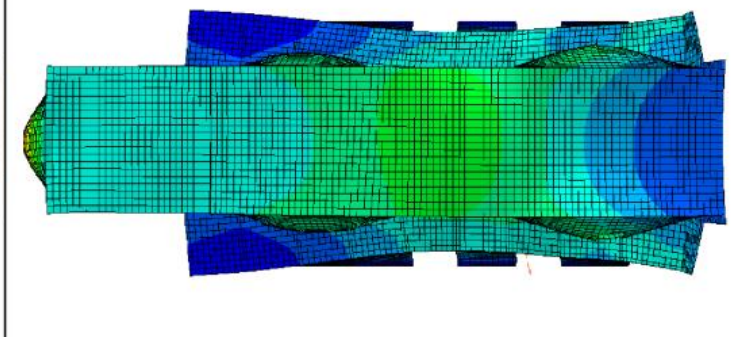

Fig. 11 Mode shapes for the different vaults modeling 

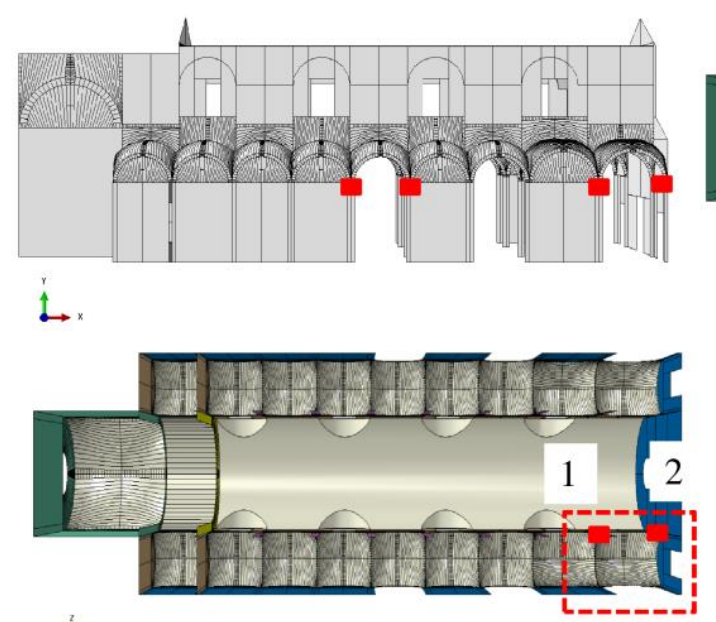

L. Columns: $\mathrm{U}_{\mathrm{z} 1}-\mathrm{U}_{\mathrm{z} 2}$

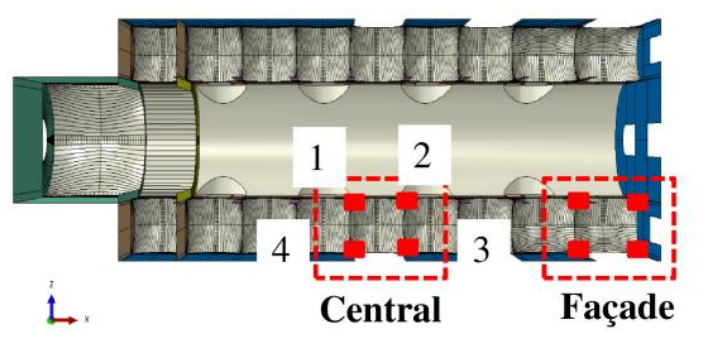

L.

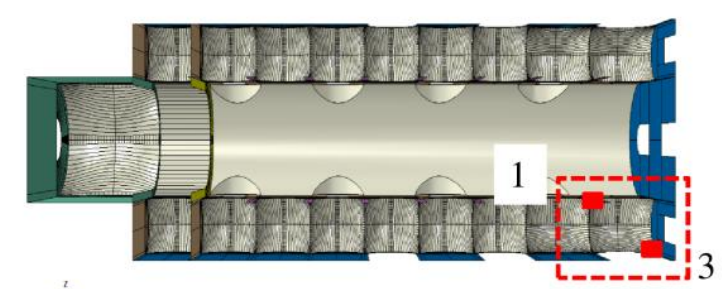

L.

Diagonal: $\mathrm{U}_{\mathrm{z} 1}-\mathrm{U}_{\mathrm{z} 3}$

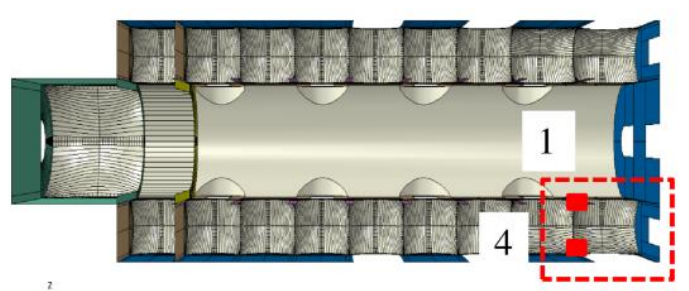

L. Transverse: $\mathrm{U}_{\mathrm{zl}}-\mathrm{U}_{\mathrm{z} 4}$

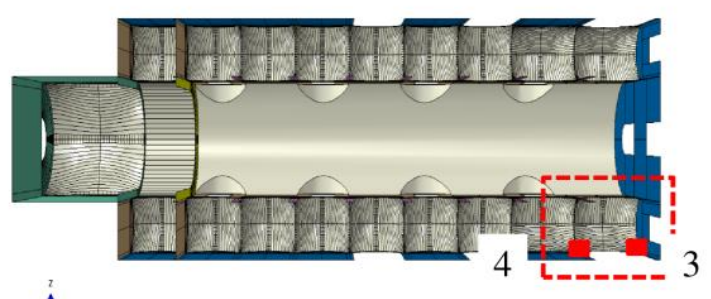

$L^{2} \quad$ External walls: $\mathrm{U}_{\mathrm{z} 1}-\mathrm{U}_{\mathrm{z} 3}$

Fig. 12 Points where relative displacements are monitored in the time-history analysis

supports/pendentives in the lateral naves are monitored in different directions: relative transverse displacements between columns, between column and external wall in diagonal direction, between column and external wall in transverse direction, between vaults support in external walls (with openings, Fig. 12). Each combination of these four points has been checked both for a vault in central area and for a vault adjacent to the façade, for a total of eight combinations for each time-history. The results of time history analyses are commented only in case of analysis in transverse direction, since, along that, relative displacements are larger and vaults play a more relevant role. For simplicity, the interaction of effects in the two main directions has been neglected.

Generally, the VET model correctly reproduces the peak relative displacements, even though not always the history displacement is similar. Nevertheless, this should be expected, due to the strong simplification introduced. Figs. 13-14-15 display an excellent agreement between maximum relative displacements of the complete model and those of VET model.

The displacement peaks are always higher in the simplified model, and this is in favor of safety. Moreover, it confirms the modal analysis results where the VET model is more flexible and "time saving" than the complete one. Nevertheless, transverse displacements are generally not correctly reproduced by the simplified model and underestimated, probably because the connection between transverse point (1 and 4 in Fig. 12) is direct, while in the real model the arch is more flexible.

An useful application of time-history analyses with simplified models is that aimed to assess the benefits offered by strengthening measures. In particular, steel tierods with $20 \mathrm{~mm}$ of diameter have been implemented in numerical simulations as preventive safety features (De Falco et al. 2013).

Also in this case, a complete model has been analyzed with steel tie-rods as axial connectors CONN3D2, defined by a stiffness value (Abaqus CAE 6.12). The complete retrofitted model has been compared to the simplified one, where the equivalent trusses have an increased stiffness considering the effect of the steel tie-rods.

The comparisons are presented in terms of two design ratios:

- R: ratio between maximum displacements with steel tie-rods and without them for the full modeled church

$$
\mathrm{R}=\frac{\delta_{\max , T I E-R O D S}}{\delta_{\max }}
$$

- $R_{V E T}$ : ratio between maximum displacements with steel tie-rods and without them for the simplified church with VETs

$$
\mathrm{R}_{V E T}=\frac{\delta_{\max , T I E-R O D S}^{V E T}}{\delta_{\max }^{V E T}}
$$




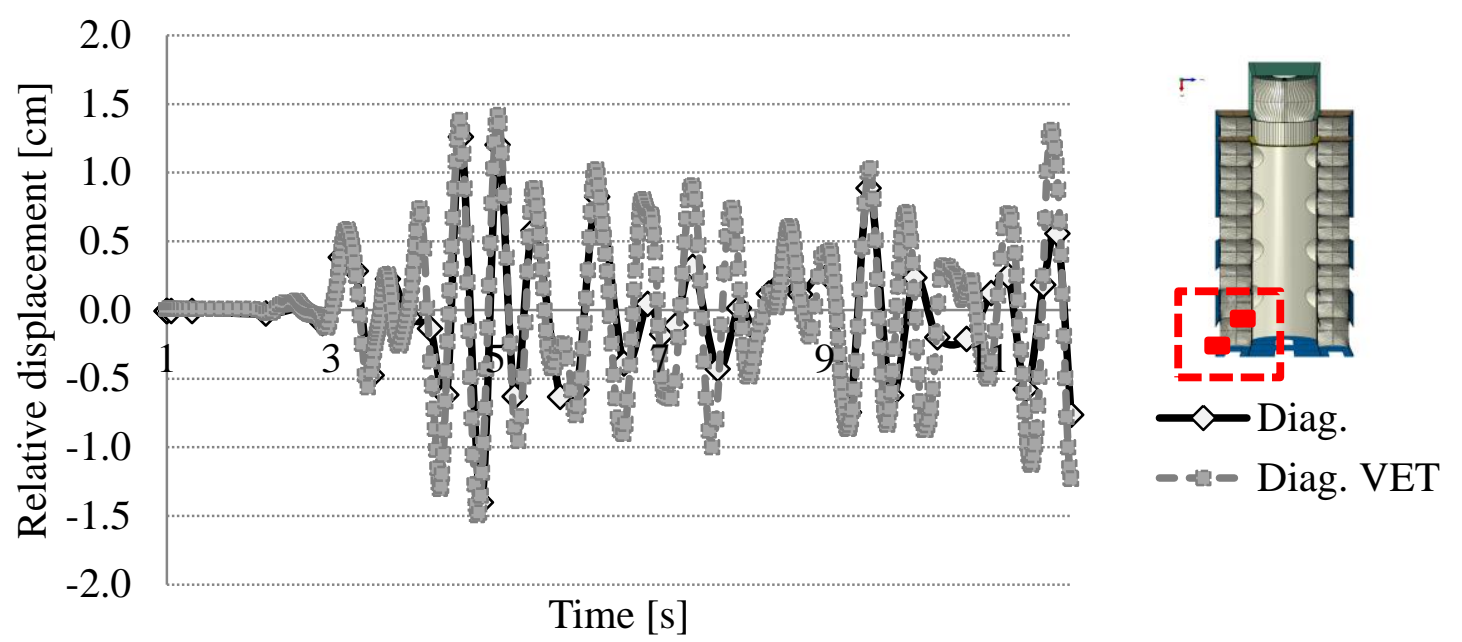

Fig. 13 Relative transverse displacements in diagonal direction (vault adjacent to the main façade): comparison between complete model and VET model - TH2 (TH: acceleration time-history)

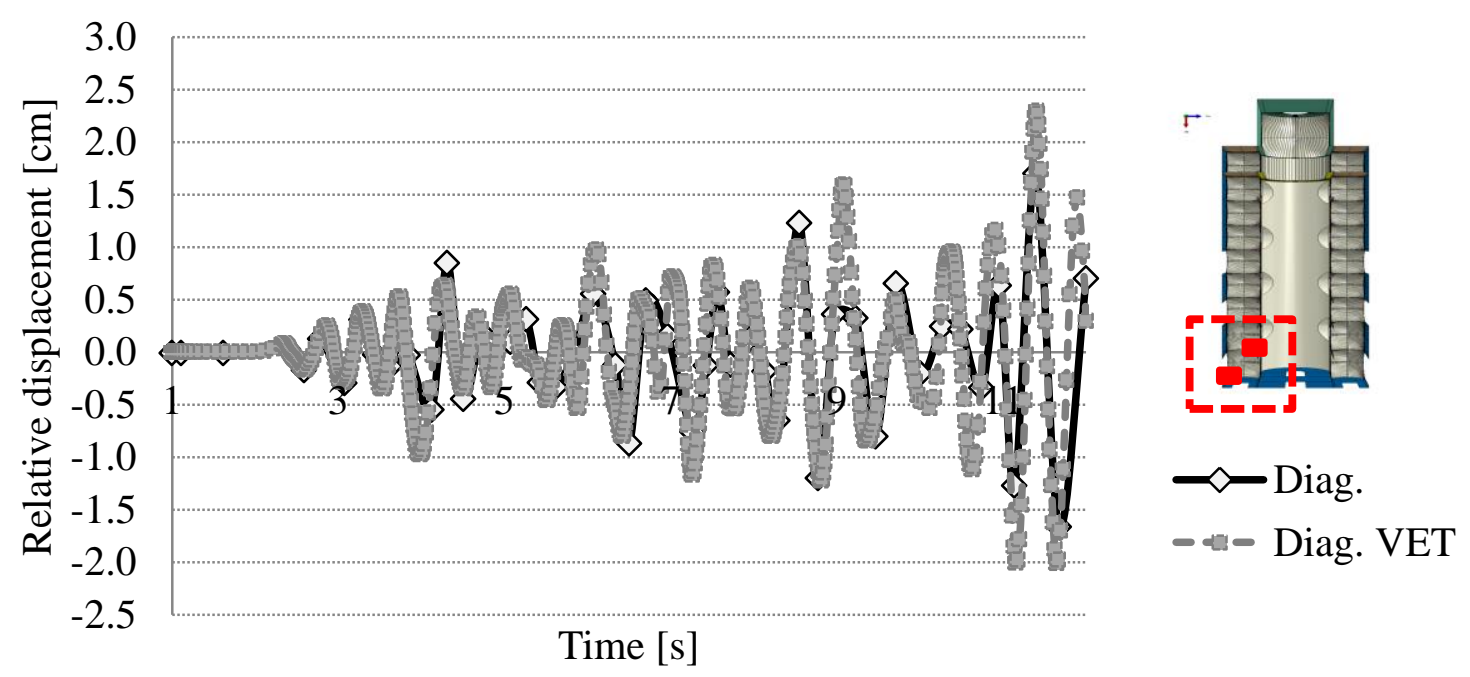

Fig. 14 Relative transverse displacements in diagonal direction (vault adjacent to the main façade): comparison between complete model and VET model - TH3 (TH: acceleration time-history)

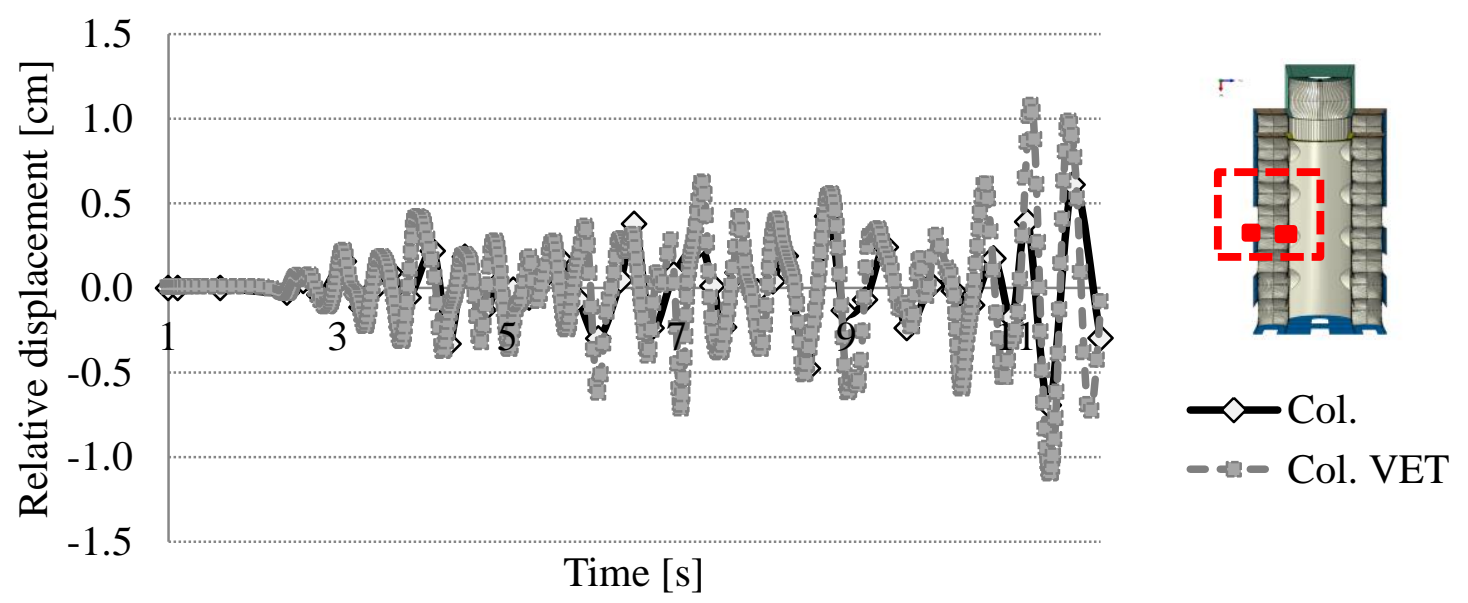

Fig. 15 Relative transverse displacements between columns top (central part of lateral nave): comparison between complete model and VET model - TH3 (TH: acceleration time-history) 


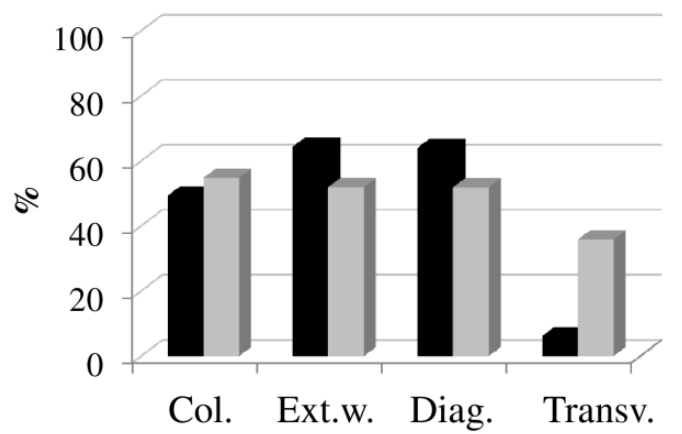

Vault adjacent to façade

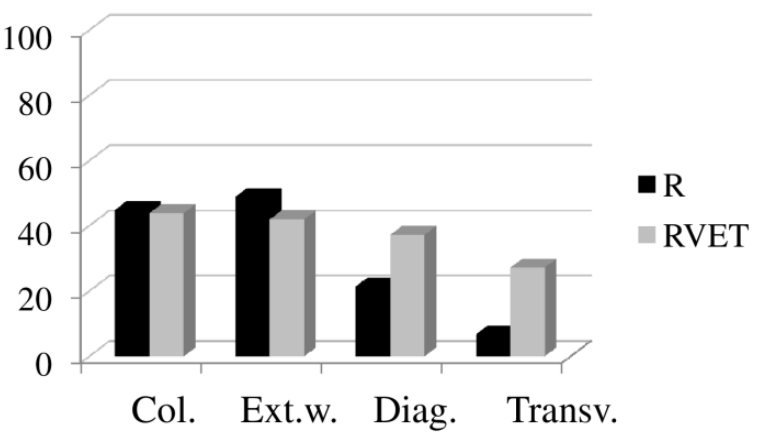

Central vault

Fig. 16 Design ratios in the complete model and in the VET model for the different monitoring point: average values of relative displacement reduction in the four time-histories

The main interest of the structural designer is indeed, among others, to assess the reduction of relative displacements of the vaults to avoid the moving away of the pendentives, for which the thrust is not contrasted and collapse mechanisms could take place.

The same time-histories analysis have been performed for the retrofitted configuration and the average of maxima displacements plotted for each monitoring position (Fig. 12). The results are displayed in Fig. 16. It is worthy to notice that the agreement is very good for the vault adjacent to the façade, with differences lower than $10 \%$ of rate reduction. In addition, the reduction for the VET model (in red in the figure) is generally lower than that for the complete model, and this is in favor of safety. Nevertheless, the method is not able to completely describe the response in the transverse direction for both areas. The strong difference between $\mathrm{R}$ and $\mathrm{R}_{\mathrm{VET}}$ is due to an accumulated effect: from one side $\delta_{\max , T I E-R O D S}^{V E T}>\delta_{\max , T I E-R O D S}$ and from the other $\delta_{\max }^{\mathrm{VET}}<\delta_{\max }$. This results in $\mathrm{R}_{\mathrm{VET}} \gg \mathrm{R}$ and therefore if the transverse relative displacement is considered, the VET model is not in favor of safety.

Finally, in all those analyses the computing resources by VETs models with respect to complete FE models are very low: computational time is less than $10 \%$ for VETs compared with complete models and in most cases this aspect is crucial for designers, joined to the simplicity in use. The VET approach then leads to an estimate of the structural response and is a step forward in comparison to the general approach where equivalent slabs are used.

\section{Conclusions}

The problem of assessing seismic vulnerability of historic buildings with masonry vaults is of great relevance. Structural designers need to have simple but effective numerical tools to perform analysis of global and/or local model of historic masonry structures. A macro-element with a system of trusses equivalent to vaults has been proposed to reduce complexity and modeling and computational time. Indeed, often masonry structures have many and complex vaults, whose role cannot be neglected in the seismic behavior. The method to identify the equivalent stiffness and steel diameter, that can be easily included in commercial programs, is described focusing on the common vaults features found in the architectural heritage. Geometrical and mechanical properties, boundary conditions and backfill influence the stiffness determination. A parametric analysis was performed to account for them, both in linear and non-linear range. Whether a brittle behavior in tension is assumed for masonry, the equivalent stiffness markedly drops for small relative displacements. The way to use vaults equivalent trusses in both global and local analysis - rocking and kinematic - has then been illustrated. A case study was analyzed to validate the equivalence between full models, where vaults are modeled with finite elements recreating their geometry, and simplified models with VETs. Modal analysis showed a very good agreement between complete and simplified model. This analysis also highlighted that, whether vaults are not modeled at all or they are modeled as diaphragms, results are not compatible with those of the reference model. Time-histories analysis was also carried out to compare relative displacements histories, generally with good agreement. This method was also demonstrated to be rapid and effective to evaluate the reduction rate of maxima displacements with a configuration of steel tie-rods in the lateral naves of the church.

\section{Acknowledgements}

This research has been supported by the Italian Network of Seismic Engineering University Laboratories (ReLUIS), Masonry Structures.

\section{References}

Abaqus CAE 6.12, User's and Theory Manuals.

Alecci, V., Focacci, F., Rovero, L., Stipo, G. and De Stefano, M. (2016), "Extrados strengthening of brick masonry arches with PBO-FRCM composites: experimental and analytical investigations", Compos. Struct., 149, 184-196.

Andreini, M., Conti, T., Masiello, G., Sassu, M. and Vezzosi, A. 
(2010), "La Chiesa Di Santa Gemma a Goriano Sicoli (Aq): Input Sismico e Meccanismi Di Danno", Design for rehabilitation of masonry structures, 4, 1-12.

Andreini, M., De Falco, A., Giresini, L. and Sassu, M. (2014), "Structural damage in the cities of Reggiolo and Carpi after the earthquake on May 2012 in Emilia Romagna", Bull. Earthq. Eng., 12(5), 2445-2480.

Caddemi, S., Caliò, I., Cannizzaro, F. and Pantò, B. (2014), "The Seismic Assessment of Historical Masonry Structures", Proceedings of Twelfth International Conference on Computational Structures Technology, Naples, Italy, September.

Caddemi, S., Caliò, I., Cannizzaro, F., Occhipinti, G. and Pantò, B. (2015), "A Parsimonious Discrete Model for the Seismic Assessment of Monumental Structures", Proceedings of the Fifteenth International Conference on Civil, Structural and Environmental Engineering Computing, Stirlingshire, UK.

Caliò, I., Marletta, M. and Pantò, B. (2012), "A new discrete element model for the evaluation of the seismic behaviour of unreinforced masonry buildings", Eng. Struct., 40, 327-338.

D'Ayala, D.F. and Tomasoni, E. (2011), "Three-dimensional analysis of masonry vaults using limit state analysis with finite friction", Int. J. Archit. Herit., 5(2), 140-171.

De Falco, A., Giresini, L. and Sassu, M. (2013), "Temporary preventive seismic reinforcements on historic churches: numerical modeling of San Frediano in Pisa", Appl. Mech. Mater., 351-352, 1393-1396.

DeJong, M.J. and Dimitrakopoulos, E.G. (2014), "Dynamically equivalent rocking structures", Earthq. Eng. Struct. Dyn., 43(10), 1543-1563.

Eurocode 8 (2003), Design Provisions for Earthquake Resistance of Structures. Part 1.1: General Rules, Seismic Actions and Rules for Buildings, European Committee for Standardization; Brussels, Belgium.

Giresini, L. (2015), "Energy-based method for identifying vulnerable macro-elements in historic masonry churches", Bull. Earthq. Eng., 44(13), 2359-2376.

Giresini, L. and Sassu, M. (2016), "Horizontally restrained rocking blocks: evaluation of the role of boundary conditions with static and dynamic approaches", Bull. Earthq. Eng., 15(1), 385-410.

Giresini, L., Butenweg, C., Andreini, M., De Falco, A. and Sassu, M. (2014), "Numerical calibration of a macro-element for vaulted systems in historic churches", Proceedings of Structural analysis of historical constructions, SAHC, Mexico City, Mexico.

Giresini, L., Fragiacomo, M. and Lourenço, P.B. (2015), "Comparison between rocking analysis and kinematic analysis for the dynamic out-of-plane behavior of masonry walls", Earthq. Eng. Struct. Dyn., 44(13), 2359-2376.

Giresini, L., Fragiacomo, M. and Sassu, M. (2016), "Rocking analysis of masonry walls interacting with roofs", Eng. Struct., 116, 107-120.

Krajewski, P. and Hojdys, Ł. (2015), "Experimental studies on buried barrel vaults", Int. J. Archit. Herit., 9(7), 834-843.

Magenes, G. and La Fontana, A. (1998), "Simplified nonlinear seismic analysis of masonry buildings", Proceedings of British Masonry Society 8.

Marseglia, P.S., Micelli, F., Leone, M. and Aiello, M.A. (2014), "Modeling of masonry vaults as equivalent diaphragms", Key Eng. Mater., 628, 185-190.

Milani, E., Milani, G. and Tralli, A. (2008), "Limit analysis of masonry vaults by means of curved shell finite elements and homogenization", Int. J. Solid. Struct., 45(20), 5258-5288.

NTC (2008), "Approvazione delle Nuove Norme Tecniche per le Costruzioni”, Gazzetta Ufficiale della Repubblica Italiana n. 29, February, 28th 2008.
Pantò, B., Cannizzaro, F., Caddemi, S. and Caliò, I. (2016), "3D macro-element modelling approach for seismic assessment of historical masonry churches", Adv. Eng. Softw., 97, 40-59.

Rossi, M. (2015), "Evaluation of the seismic response of masonry cross-vaults", Ph.D. Dissertation, University of Genova, Genova.

$C C$ 